\title{
Ещенко В.Р., Щербакова М.В. \\ Развитие у старшеклассников критического мышления в процессе работы с художественным текстом на иностранном языке
}

ФГБОУ ВО «Воронежский государственный университет» (Россия, Воронеж)

doi: 10.18411/lj-04-2021-148

\section{Аннотация}

В статье технология развития у старшеклассников критического мышления в процессе работы на уроках английского языка с художественным текстом; показано как на практике в процессе развития у обучающихся умений чтения на иностранном языке в соответствии со стадиями развития критического мышления используются приёмы и формы работы, активизирующие мыслительные процессы.

Ключевые слова: критическое мышление, художественный текст на английском языке, обучение иностранному языку.

\section{Abstract}

The article presents techniques for developing critical thinking with the use of fictional texts in the English classroom for high school students; it demonstrates how to use different tasks and methods according to the stages of developing critical thinking that activate students' ways of thinking .

Keywords: critical thinking, fictional text in English, teaching English language.

Назначение периода юности в жизни каждого человека состоит в том, чтобы расширить горизонты познания реального мира, других людей и себя самого, выработать ко всему этому свое отношение, найти свое место в обществе и определить жизненные задачи. Отсюда - интерес старшеклассников (16-17 лет) к самым общим, универсальным законам природы и человеческого бытия, острый интерес к познанию человеческих возможностей и внутреннему миру человека, склонность к самоанализу и самооценке.

Старшеклассники не просто строят общую картину мира, но вырабатывают собственное отношение ко всему, что слышат или видят. В процессе умственной деятельности у них сочетаются активность анализирующей мысли, склонность к рассуждениям и особые эмоциональность и впечатлительность. В этом возрасте отмечается улучшение коммуникативных умений, большая дифференцированность эмоциональных реакций и способов выражения эмоциональных состояний, повышение самоконтроля и саморегуляции.

Рассмотренные особенности развития интеллектуально-познавательной сферы личности старшего подростка отражаются на всех видах его учебной деятельности при усвоении иностранного языка. На занятиях по иностранному языку старшеклассников отличает активность мышления, направленность на решение мыслительных задач, вкус к логическому упорядочиванию и систематизации, к поиску универсальных закономерностей, к самостоятельному нахождению способов обобщенной ориентировки в материале, к теоретическим обобщениям. Эффективность усвоения и закрепления старшеклассниками иноязычного материала прямо зависит от интенсивности и серьезности их мыслительной работы - наиболее важного компонента интеллектуально-познавательной деятельности.

Огромный обучающий и развивающий потенциал содержит организация общения на занятиях по иностранному языку. Однако этот потенциал реализуется только при соответствующей возрасту учащихся организации этого вида деятельности. Старшеклассники с их возросшей умственной пытливостью не принимают информационно обедненные формы работы (сюда относится многократное повторение 
уже известного, чисто формальные преобразования содержания и т.п.). Им импонирует такая организация общения на занятиях, когда происходит выбор между различными точками зрения, сопоставление альтернативных подходов, отстаивание своей точки зрения, дискуссия. Как пишет И.С. Кон, единственный способ вызвать глубокий эмоциональный и нравственный отклик подростка, юноши - поставить его перед близкой ему проблемой, заставляющей самостоятельно размышлять и формулировать вывод [4]. Организация такой содержательной интерпретации материала, которая включает сопоставление различных позиций, мнений, точек зрения, в принципе возможна при работе с любой тематикой.

Таким образом, развитие у старшеклассников критического мышления зависит от реализации в образовательном процессе следующих педагогических условий:

- развитие интеллектуальной сферы и критического мышления, в частности, будет принята как специальная цель обучения иностранному языку;

- в содержательном аспекте развивающего обучения иностранному языку будут выделены познавательные средства и способы теоретической деятельности, а в процессуальном - организовано усвоение этих средств и способов; спроектирована технология развития критического мышления (ТРКМ) как система ситуаций, востребующих проявление в образовательном процессе мыслительных навыков, познавательных и учебных умений, предметных и внепредметных знаний;

- процесс обучения иностранному языку будет выстроен в виде системы личностно ориентированных ситуаций, предполагающих: проблемнопоисковую подачу учебного материала; предъявление творческих заданий межпредметного характера для развития умения переноса знаний и навыков в новую ситуацию; использование дискуссий, деловых и ролевых игр, с целью актуализации потребности пользоваться иностранным языком как средством общения.

По мнению ученых (И.О. Загашев, С.И. Заир-Бек, Д. Клустер, Д. Халперн и др.), характерными особенностями критического мышления являются оценочность, открытость новым идеям, собственное мнение и рефлексия собственных суждений. С.И. Зар-Бек обращает внимание на то, что критическое мышление - это открытое мышление, не принимающее догм, развивающееся путем наложения новой информации на жизненный и личностный опыт [1]. Критическое мышление иногда называют направленным мышлением, поскольку оно направлено на получение желаемого результата [5].

Цель ТРКМ состоит в развитии мыслительных навыков, которые необходимы обучающимся в дальнейшей жизни (умение принимать взвешенные решения, работать с информацией, выделять главное и второстепенное, анализировать различные стороны явлений). Актуальность использования данной технологии в процессе обучения иностранному языку обусловлена тем, что она позволяет проводить занятия в оптимальном режиме, у обучающихся повышается работоспособность, усвоение знаний на уроке происходит в процессе постоянного познавательного поиска.

Технология развития критического мышления направлена на развитие интеллектуальной сферы старшеклассника, к основным показателям которого нами отнесены: умение оценивать; быть открытым всему новому; иметь собственное мнение по обсуждаемым проблемам, а также рефлексия собственных суждений и достижений.

Данная технология использована нами на уроке английского языка в 11 классе МБОУ «Лицей №1», г. Воронеж в процессе работы учащихся с художественным текстом. В УМК «Spotlight» для учащихся 11 класса есть специальный раздел для развития умений чтения, в котором представлены тексты из известных произведений английской классической литературы [6]. С целью развития у обучающихся 
критического мышления в процессе овладения умениями изучающего чтения мы предложили отрывок из произведения Чарльза Диккенса «Большие надежды» (англ. "Great Expectations" by Charles Dickens).

Основу технологии развития критического мышления составляет базовый дидактический цикл, состоящий из трех фаз (стадий) [1].

I фаза (5 минут): Вызов (пробуждение имеющихся знаний интереса к получению новой информации).

II фаза (30 минут): Осмысление содержания (получение новой информации).

III фаза (10 минут): Рефлексия (осмысление, рождение нового знания).

Развитие у старшеклассников критического мышления протекало в соответствии с названными фазами (стадиями):

\begin{tabular}{|c|c|c|c|}
\hline \multicolumn{2}{|c|}{ I фаза } & II фаза & III фаза \\
\hline $\begin{array}{c}\text { Opinion based on the } \\
\text { title }\end{array}$ & $\begin{array}{l}\text { Opinion based on the } \\
\text { picture }\end{array}$ & Text & $\begin{array}{c}\text { Opinion based on the content of the } \\
\text { whole book }\end{array}$ \\
\hline
\end{tabular}

До начала работы с текстом, обучающимся предлагается таблица, которую им необходимо заполнить до, в процессе и после чтения текста:

- суждение, основанное на названии книги;

- суждение, основанное на иллюстрации к тексту;

- суждение, основанное на прочитанном отрывке из текста;

- суждение, основанное после прочтения всей книги.

I Фаза. ВЫЗОВ. Задачи этой стадии: 1) постановка целей урока, т.е. процесс целеполагание как учителя, так и обучающихся; 2) активизация познавательной деятельности обучающихся. Рекомендуем использовать прием «Мозговой штурм» или «групповая мозговая атака».

Обучающиеся работают в группах. Первая групnа отвечает на вопросы, связанные с названием книги и её автором: Что вы знаете об авторе? Какие произведения этого автора вам известны? Как вы понимаете название книги? Что вы ожидаете от сюжета книги?

Вторая групnа отвечает на вопросы, касающиеся иллюстрации к тексту: Посмотрите на рисунок и скажите, что по вашему мнению происходит? Где находятся герои? Почему они встретились в этом месте?

Обучающиеся, слушая ответы друг друга, и заполняют первые две колонки таблицы. Если сравнить высказывания учащихся 1-ой и 2-ой группы, то можно заметить, что у учащихся первой группы сформировано положительное отношение к содержанию текста, в то время как у учащихся второй - отрицательное. Для того, чтобы учащиеся смогли подтвердить свои суждения и понять содержание текста на уровне критического осмысления, переходим к следующей, II фазе, - ОСМЫСЛЕНИЕ (работа с текстом), главной задачей которой является отслеживание того, как осуществляется процесс понимания изучаемого материала. Постановка целей в процессе знакомства с новой информацией осуществляется при ее наложении на уже имеющиеся знания. На данном этапе мы рекомендуем использовать такой прием как «Чтение с остановками».

После прочтения мини-диалога обучающиеся высказывают своё мнение, отвечая на вопросы: Зачем мужчина хочет узнать имя мальчика? Является ли это простой вежливой формальностью или же он преследует какие-то цели? Отпустит ли мужчина мальчика?

После прочтения половины предложенного текста, опираясь на механизм вероятностного прогнозирования, учащиеся отвечают на вопрос: «Как, по вашему мнению, завершится данная сцена?». А по завершению чтения сравнивают свои гипотезы с полученной из текста информацией и делают вывод о том, верны ли их суждения. 
III Фаза - это тщательное ВЗВЕШИВАНИЕ, ОЦЕНКА И ВЫБОР. В процессе рефлексии та информация, которая была новой, становится присвоенной, превращается в собственное знание. Она становится основной целью деятельности учащихся и учителя. Метод взаимодействия учащихся, который используется на данном этапе, дискуссия.

Возвращаясь к таблице, предложенной в начале работы с художественным текстом, обучающиеся снова высказывают свои мнения: Какие персонажи, на ваш взгляд, положительные, а какие отрицательные? Почему? Проведите параллель между названием текста и прочитанным отрывком. Захотелось ли Вам прочитать книгу полностью? Можем ли мы судить о книге, опираясь лишь на прочитанный отрывок?

Заполнив таблицу полностью, обучающиеся приходят к выводу, что мнение, основанное на иллюстрации к тексту, совпадает с мнением после прочтения отрывка и оно отрицательное. Однако, те обучающиеся, которые оказались знакомы с целым произведением, заметили, что мнение, основанное на названии книги, и их мнении обо всей книге совпадает - и оно положительное.

Таким образом, использование в обучении английскому языку технологии критического мышления способствует развитию у обучающихся таких умений как: задавать вопросы; самостоятельно формулировать гипотезы; предлагать пути решения проблем; высказывать собственное мнение на основе осмысления различного опыта, идей и представлений; аргументировать свою точку зрения и учитывать мнения других; брать на себя ответственность; участвовать в совместном принятии решения; проектировать собственную образовательную траекторию (академическая мобильность).

$$
* * *
$$

1. Загашев И.О. Критическое мышление: технология развития / И.О. Загашев, С.И. Заир-Бек. - СПб: Альянс-Дельта, 2003. - 284 с.

2. Заир-Бек С.И. Развитие критического мышления на уроке / С.И. Заир-Бек, И.В. Муштавинская. М.: Изд-во «Просвещение», 2004. - 192 с.

3. Клустер Д. Что такое критическое мышление / Д. Клустер. - М.: ЦГЛ, 2005. - С. 5 - 13.

4. Кон И.С. Психология старшеклассника / И.С. Кон. - М.: Просвещение. - 1982. - 191 с.

5. Халперн Д. Психология критического мышления / Д. Халперн. - СПб., 2000. - 126 с.

6. Spotlight 11: Student's Book / Английский язык. 11 класс. - М.: Просвещение, Express Publishing, 2011. - $244 \mathrm{c}$.

Идиатуллина Л.Е. ${ }^{1}$, Караваева Т.В. ${ }^{2}$

Влияние педагогических технологий на развитие познавательных способностей детей старшего дошкольного возраста (на примере игры русские шашки)

${ }^{1}$ ГБУ ДПО «Челябинский институт переподготовки и повышения квалификации работников образования» (Россия, Челябинск)

${ }^{2}$ МДОУ «Детский сад № 7» Копейского городского округа

(Россия, Копейск)

doi: 10.18411/lj-04-2021-149

\section{Аннотация}

В статье раскрывается влияние настольной игры русские шашки на развитие познавательных способностей детей старшего дошкольного возраста. Успешности обучения игре в русские шашки способствуют педагогические условия, педагогические технологии, которые реализует в своей деятельности педагог дополнительного образования.

Ключевые слова: дополнительное образование детей, игра в русские шашки, познавательные способности, педагогические технологии, педагогические условия. 